\title{
WHAT DO TEENAGERS PARENTS KNOW ABOUT DRUG USE AND HOW DO THEY UNDERSTAND PREVENTING IT?
}

\author{
Alina Costin, Liliana Renate Bran
}

„Aurel Vlaicu” University of Arad, Romania

\begin{abstract}
Introduction On one hand, drug use has become an extremely welcomed subject because it „needs to be", and because it has to be treated seriously; on the other hand, it is addressed to with great ignorance among all the actors directly involved in handling this phenomenon. The problem of drug use, with all the dimensions of it, must take care of this behavior and it can be classified as mental health problems, which will have multiple consequences for their care in the health plan. Literature has already become a classic, such as Learning Theories (Bandura, 1986, Skinnere, Thorndike, etc.), Family-Based Theories and Systemic Approach (Waldrom, 1998), and more recent works by Stephen J. Bahr, John P. Hoffmann, Xiaoyan Yang, stresses the role of the family in building child protection factors for substance use. The purpose of this research is to investigate the parents of the high school students in Arad Municipality regarding the information they have about drugs, their perception related to their child's relationship with drugs and how they "treat" this topic.

Design The qualitative information we want to obtain has imposed a specific design for qualitative research. The study is descriptive and has a practical orientation- it was carried out between June and September 2019.

Methodology - We have created 8 focus groups with parents of high school students with different demographic characteristics (level of education, religion, provenance, family status) and we have made 3 profound interviews for each category of people we have selected. This paper presents the preliminary qualitative results of a study that is still in progress. The focus groups carried out indicates that the vast majority of parents treat this topic of consumption superficially. Their parenting principle is based on building a strong, positive and open relationship, but the child is a fundamental premise in preventing any deviat behavior. But they have as a parenting principle that to build a strong positive, open and dialogue relationship, but the child, which is a fundamental premise in preventing any deviant behavior. The originality of this study and why it was realised is due to the lack of information upon this subject, at least in this city, Arad, and the main limitations consit in the imposibility of generating the conclusions regarding the whole population concerned.
\end{abstract}

Key words: drug use, preventing, family, protection factors 